\title{
Fuzzy VIKOR Approach to Evaluate the Information Security Policies and Analyze the Content of Press Agencies in Gulf Countries
}

\author{
Amir Mohamed Talib \\ Information Technology Department, College of Computer and Information Sciences (CCIS), Al Imam Mohammad Ibn Saud \\ Islamic University (IMSIU), Riyadh, KSA \\ Email: ganawa53@yahoo.com
}

How to cite this paper: Talib, A.M. (2020) Fuzzy VIKOR Approach to Evaluate the Information Security Policies and Analyze the Content of Press Agencies in Gulf Countries. Journal of Information Security, 11, 189-200.

https://doi.org/10.4236/jis.2020.114013

Received: August 13, 2020

Accepted: September 20, 2020

Published: September 23, 2020

Copyright $\odot 2020$ by author(s) and Scientific Research Publishing Inc. This work is licensed under the Creative Commons Attribution International License (CC BY 4.0).

http://creativecommons.org/licenses/by/4.0/

\begin{abstract}
A news agency is an organization that gathers news reports and sells them to subscribing news organization, such as newspapers, magazines, radio and television broadcasters. A news agency may also be referred to as a wire service, newswire, or news service. The main purpose of this paper is to evaluate the security policies and analyze the content of five press agencies in gulf countries which are (Kuwait News Agency (KUNA), Emirates News Agency (WAM), Saudi Press Agency (SPA), Bahrain News Agency (BNA), and Oman News Agency (OMA)) by using a fuzzy VIKOR approach where linguistic variables are applied to solve the uncertainties and subjectivities in expert decision making. Fuzzy VIKOR approach is one of the best Multi-Criteria Decision Making (MCDM) techniques working in fuzzy environment. This study benefits security and content analysis experts know which press agency has the mandate and the competence to educate the public on news agencies. Besides, this paper contributes to Gulf agencies in helping them in their resolve to ensure the quality of content information and information security policies over the internet.
\end{abstract}

\section{Keywords}

Content Analysis, Fuzzy VIKOR Approach, Gulf Countries, Information Security Policy, Press Agencies, Multi-Criteria Decision Making (MCDM), Online Information Quality

\section{Introduction}

The internet is often termed a disruptive technology, referring to its game-changing impact on communications markets. But the internet has the 
potential to be disruptive in more ways than one: as well as bringing opportunities for economic growth, access to information, and being a crucible for innovation, it can additionally be perceived as disrupting the concord of societies, undermining hard-won stability or even offering a haven for crime and extremism [1]. Internet penetration rates are especially excessive in the Gulf, and have grown hastily over the past five years [2].

In today's world of biases and false information, a news agency is the only ray of hope to disseminate authentic and impartial information. Also known as a press, a news agency is an organization that gathers news stories and sells them to subscribing news agencies, such as newspapers, magazines and newspapers. As a result, all media depend on agencies for most of the information, especially those who cannot afford offices outside their home city. News agencies are also a reliable source of information for the media and people to stay abreast of international news [3].

Security in accordance with is the act of being impenetrable from harm or danger, protection, defense, and renovation of values, and the absence of threats to obtained values [4]. Security is about survival and the condition of human existence. Security additionally exists when people stay collectively in a sure environment besides disturbance or violence. In the identical vein [5], it is stated that security is the act of maintaining peace within the governing territories. This is generally accomplished through upholding the national regulation and defending the inside security threats in specific areas of the country. Accordingly, also security is viewed as freedom from danger or threats, and the ability of a nation to protect and develop itself, promote and cherish values and legitimate interests and enhance the well-being of its people [6]. This can be maintained through internal security system. Usually, inner security system in any society is very necessary due to the fact that it is used to prevent violence and criminal activities in one-of-a-kind societies. Internal security additionally ensures freedom of people from any criminal disturbances and ensures the absence of criminal inclinations which can undermine internal brotherly love and co-operate existence of the nation and its capability to keep its core values and meet the respectable aspiration of the people.

A security policy is a set of policies for deciding the most permissible get entry to rights for a specific procedure to a precise segment, given the attributes of each the system and the segment. Traditionally security policy has three desires namely: Confidentiality, Integrity and Availability [7].

Content analysis is a research technique used to examine countless texts. In the past, content analysis was primarily used to study texts from traditional media such as newspapers, television and radio programs. At present researchers continue to analyze texts obtained from the new media that include the World Wide Web [8]. Content analysis is a research tool used to determine the presence of effective phrases or thoughts of internal texts or units of texts. Researchers quantify and analyze the presence, meanings and relationships of such phrases and concepts, then make inferences about the messages inner the texts, 
the writer(s), the audience, and even the subculture and time of which these are a part. Texts can be described typically as books, e-book chapters, essays, interviews, discussions, newspaper headlines and articles, historic documents, speeches, conversations, advertising, theater, informal conversation, or sincerely any incidence of communicative language [9]. Texts in a single learn about would possibly additionally moreover symbolize a variety of special types of occurrences, such as Palmquist's 1990 find out about two composition classes, in which he analyzed student and trainer interviews, writing journals, lecture room discussions and lectures, and out-of-class interaction sheets. To habits a content analysis on any such text, the textual content is coded, or damaged down, into manageable training on a variety of levels-word, phrase sense, phrase, sentence, or theme-and then examined the usage of one of content fabric analysis' predominant methods: conceptual analysis or relational analysis [10].

Gulf nations have developed long-term strategic visions for transformation, which embody plans to diversify sources of wealth, decorate health and education and in some instances (e.g. Saudi Arabia and UAE) transition to a "knowledge society". There is proof of a fine correlation between financial expansion and internet uptake. The Gulf countries' strategic plans apprehend that to affect transformation, improvement is required on numerous fronts: infrastructure, skills (including the potential for scientific research and innovation) and economic resource [11].

The motive of this paper is to consider the security policies and analyze the content of five press agencies in gulf countries which are (Emirates News Agency (WAM), Kuwait News Agency (KUNA), Saudi Press Agency (SPA), Bahrain News Agency (BNA), and Oman News Agency (OMA)) via the usage of a fuzzy VIKOR approach, that regarded as one of the best of Multi-Criteria Decision Making (MCDM) strategies working in fuzzy environment.

\section{Gulf Press Agencies}

\subsection{Emirate News Agency (WAM)}

WAM was launched in November 1976. The agency which is headquartered in Abu Dhabi is part of National Media Council. On 18th June, 1977, WAM started out to fulfill its professional mandate by means of transmitting UAE news to the rest of the world, overlaying all aspects of its political, economic and social development. WAM is ever evolving, and has viewed many large accomplishments over the years which have resulted in its capability to share important news, photographs and video material regarding the state from a single source [12]. WAM is like Saudi news agency, collects news and works as information provider to different media. WAM has six types of news which are: 1) Political news, 2) Business news, 3) Tech news, 4) Sport news, 5) Health news, and 6) Weather news.

\subsection{Kuwait News Agency (KUNA)}

KUNA is a news agency founded in Kuwait. It used to be established on October 
6, 1979 in accordance with an Amiri Decree to acquire news and information and distributing it to media establishments and individuals. However, it functions as a branch of the Ministry of Information, although it has an independent budget [13]. The agency goal is to gather and generate news for distribution to individuals and media institutions. This provides an objective service which focus mostly on Kuwait's just causes regionally and internationally. KUNA has six types of news which are: 1) Political news, 2) Business news, 3) Tech news, 4) Sport news, 5) Health news, and 6) Weather news.

\subsection{Saudi Press Agency (SPA)}

The Saudi news agency was established in 1970 as the first national news agency in Saudi Arabia. The agency is also the leading news agency in the Arabian Gulf region. The main and initial purpose of the SPA was to serve as a central body for collecting and disseminating local and international information in Saudi Arabia and abroad [14]. The SPA is under the responsibility of the Ministry of Culture and Information and therefore its chair reports directly to the Minister. The SPA provides newspapers with a guideline, the editorial line, which should be followed in their reports.

SPA is like any news agency, it's an association that compiles news reports and then sells them to other organizations. As a result, all media depend on agencies for most of the information, especially those who cannot afford offices outside their home city. Also, SPA is a reliable source of information for the media and people to stay abreast of Saudi Arabia news [14]. We can resume the main roles of Saudi news agency in: 1) Disseminate information from one city to another, 2) Collect news around the country that newspapers cannot afford individually, 3) Work as a provider of information to the media and 4) Be the first to report the latest news. SPA has six types of news which are: 1) Political news, 2) Business news, 3) Tech news, 4) Sport news, 5) Health news, and 6) Weather news.

\subsection{Bahrain News Agency (ONA)}

BNA is the foremost contributory of major countrywide news in the Kingdom of Bahrain by means of advantage of its honest and goal reporting. BNA is the official conveyor of Bahrain's news and occasions and the predominant source of the Kingdom's news domestically and overseas [15].

The agency purpose is to obtain, transmit and market news from unique sources, at domestic and overseas with objectivity, credibility and professionalism in addition to put together press substances (features, news analyses, photos, researches and studies) and market them at domestic and abroad. BNA has six types of news which are: 1) Political news, 2) Business news, 3) Tech news, 4) Sport news, 5) Health news, and 6) Weather news.

\subsection{Oman News Agency (ONA)}

ONA used to be mounted as per Royal Decree No. 39/86 on 29/5/1986. On 
25/6/1997, Oman Establishment for Press, News, Publication and Advertising (OEPNPA) was once as soon as established as per the Royal Decree No. 43/97. As per the equal Royal decree, Oman News Agency has been one of the units of the Oman Establishment till the issuance of the Royal Decree No. 75/2006 which transferred Oman News Agency underneath the jurisdiction of the Ministry of Information with have an effect on from 16/7/2006. Oman News Agency falls right now below the Minister of Information [16].

The agency intention is to make a contribution to creating the Omani citizen thru acquainting him/her with the local, regional and international developments [16]. ONA has six types of news which are: 1) Political news, 2) Business news, 3) Tech news, 4) Sport news, 5) Health news, and 6) Weather news.

\section{Fuzzy MCDM}

Multi-Criteria Decision Making (MCDM) as a methodological and modeling tool is used to deal with complicated selection making problems. MCDM has over the years come to be one of the most famous branches of choice making [17] [18], utilized in many disciplines. Fuzzy logic has validated to be a truly useful and surroundings pleasant way in drawing close to MCDM in prerequisites of imprecise or subjective documents in our natural language expression of thoughts and judgments. Many extended functions and theories have been carried out to take care of a variety of types of MCDM when you think about that Bellman and Zadeh [19] proposed selection making in fuzzy environment, Fuzzy logic has been prolonged to almost all MCDM strategies such as VIsekriterijumska optimizacija I KOmpromisno Resenje (VIKOR), Weighted Product Model, Technique for Order Preference by means of capability of Similarity to Ideal Solution (TOPSIS), Grey Relational Analysis (GRA), Analytic Network Process (ANP), Elimination and Choice Expressing Reality (ELECTRE), Preference Ranking Organization Method for Enrichment Evaluation (PROMETHEE) and Analytic Hierarchy Process (AHP).

\section{Fuzzy VIKOR Method}

VIKOR is a compromise rating approach added via Opricovic [20]. The VIKOR method first establishes 1) a compromise ranking-list, 2) a compromise solution, and 3) the weight steadiness intervals for the compromise solution [20] [21]. It then determines the positive-ideal solution and the negative-ideal solution to recommended beneficial aid in ranking and desire [22]. The underlying precept of the VIKOR MCDM method is to deal with rating and selection of alternatives which have multi-conflicting or non-commensurable requirements [23]. As is customary of most MCDM techniques, the VIKOR method used to be moreover prolonged to accommodate subjectivity and imprecise data underneath fuzzy environment [24].

A wide variety of features from a fluctuation of disciplines have been carried out the utilization of the fuzzy VIKOR method. In [24], fuzzy VIKOR is used in 
identifying on insurance plan diagram firms in a crew resolution making method whiles [25] employed fuzzy VIKOR to get to the backside of multi-criteria decision making problems. The method is used with the aid of [26] [27] for company decision problems. In [27], however, the method has modified the utilization of entropy measure for intention weighting. In [28] fuzzy VIKOR is utilized for optimized partners' choice in IS/IT outsourcing projects. In [29] the compromise approach is used to pick renewable electricity mission in Spain. In [30] a blended shape of fuzzy VIKOR and GRA strategies is utilized to think about company exceptional of airports, [31] utilized fuzzy VIKOR for material decision and [32] used fuzzy VIKOR in a robotic selection. Again in [33], fuzzy VIKOR chiefly primarily based definitely on DEMATEL And ANP is utilized in assessing information security hazard control. The literature reviewed portrays the underlying precept of the VIKOR approach for choosing and rating problems on the different hand seldom utilized in comparison of service quality.

\section{Fuzzy VIKOR Framework}

Fuzzy VIKOR method used in this paper is equipped in the following order. First, the criteria, options and a team of decision makers are selected. Second, the linguistic time duration sets are recognized for weights and ratings. Third, the individual linguistic preferences for necessities and alternatives are accumulated and modified into weights and decision matrix. Fourth, the weights and decision matrix are defuzzified into crisp weights and ratings. Fifth, the best and worst values are calculated in order to compute $\mathrm{Si}, \mathrm{Ri}$, and $\mathrm{Qi}$ index values. Lastly, the alternatives are ranked and for this motive a compromise solution is proposed. The small print of the framework with unique equations that are used in this paper can be determined in [34].

\section{Result}

This section illustrates how to evaluate the security policies and analyze the content of five press agencies in gulf countries which are (Emirates News Agency (WAM), Kuwait News Agency (KUNA), Saudi Press Agency (SPA), Bahrain News Agency (BNA), and Oman News Agency (OMA)) by means of the usage of a fuzzy VIKOR approach.

First, the criteria, alternatives and a group of decision makers had been selected. Fifteen criteria that have been proposed via $\mathrm{Wu}$ et al. [34] have been adopted in this study (refer to Figure 1). The criteria had been grouped into four essential clusters, credibility, content, design, and security. A group of three decision makers consist of journalists, information security professional and web designers have been chosen to consider the security policies and analyze the content of five press agencies in gulf countries. Alexa used to be used in searching for the Gulf press agencies over the Internet. The key-word "Gulf News" was entered and 313,000,000 results have been displayed. All links to research papers and news had been omitted. Links to information on news and any association 


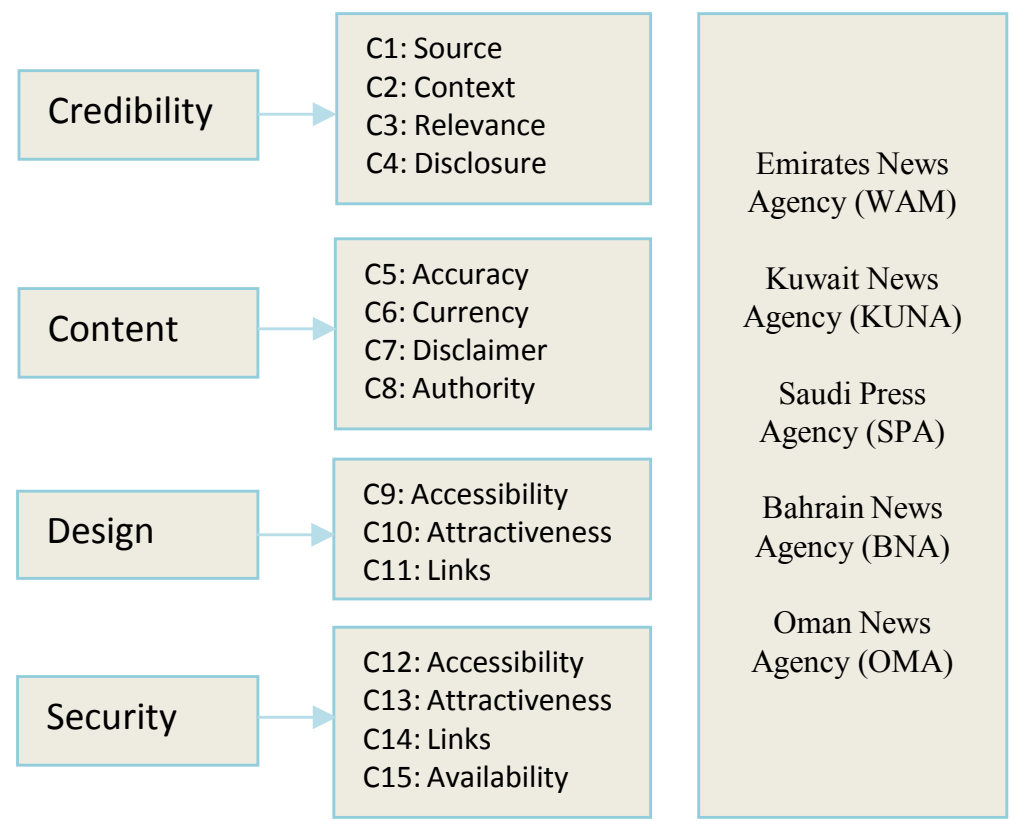

Figure 1. A framework for evaluating the security policies and analyze the content of five press agencies in gulf countries.

in gulf websites had been considered. Only websites that provided English language have been selected.

Second, the linguistic term sets were identified for weights $\left(L_{1}\right)$ and ratings $\left(\mathrm{L}_{2}\right)$ as follows:

- $\mathrm{L}_{1}=\{$ VeyHigh $(\mathrm{VH})=(0.6,0.8,1.0), \operatorname{High}(\mathrm{H})=(0.3,0.5,0.7), \operatorname{Medium}(\mathrm{M})$ $=(0.4,0.6,0.8)$, Low $(\mathrm{L})=(0.1,0.4,0.6)$, VeryLow $(\mathrm{VL})=(0.0,0.1,0.2)\}$,

- $\mathrm{L}_{2}=\{$ Excellent $(\mathrm{E})=(0.9,1.0,1.0)$, VeryGood $(\mathrm{VG})=(0.7,0.9,1.0)$, Good $(G)=(0.5,0.7,0.9)$, Fair $(F)=(0.2,0.4,0.6)$, Poor $(P)=(0.0,0.1,0.3)$, VeryPoor $(\mathrm{VP})=(0.0,0.0,0.1)\}$.

Third, the individual linguistic preferences for criteria have been collected. Table 1 indicates the evaluation of weight for each and every criterion. The method used to be repeated for the evaluation of alternatives. The linguistic preferences have been then converted into triangular fuzzy numbers for weights and alternatives with the useful resource of using $L_{1}$ and $L_{2}$ respectively. Then, the fuzzy weights for each and every criterion and the fuzzy rating for every alternative had been aggregated by means of the use of Equation (5) and Equation (6) in [34] respectively. Table 2 indicates the aggregated fuzzy decision matrix.

Fourth, the weights and ratings matrix have been defuzzified into crisp weights and ratings by using centroid method in accordance with Equation (7) in [34]. The results are proven in Table 3.

Fifth, the best and worst values for each criterion were calculated by using Equation (8) and Equation (9) in [21] respectively. Table 4 shows the best and worst values for each criterion. They were used in calculating the $S, R$ and $Q$ index values for each alternative by using Equations (10)-(12) in [34] respectively. The results are shown in Table 5. 
Table 1. Weight for each criterion.

\begin{tabular}{cccccccccccccccc}
\hline & \multicolumn{11}{c}{ Ceight for each criterion } \\
\cline { 2 - 7 } & C1 & C2 & C3 & C4 & C5 & C6 & C7 & C8 & C9 & C10 & C11 & C12 & C13 & C14 & C15 \\
\hline WAM & H & M & VH & L & M & L & H & H & VH & M & VH & VH & M & VH & H \\
KUNA & H & M & H & M & M & H & H & VH & VH & L & VH & VH & L & VH & H \\
SPA & VH & H & VH & H & M & H & H & VH & VH & H & VH & VH & H & VH & VH \\
BNA & H & L & H & M & M & M & H & H & H & VH & VH & H & VH & VH & H \\
OMA & H & M & VH & L & M & M & H & VH & VH & VH & VH & VH & VH & VH & H \\
\hline
\end{tabular}

Table 2. Aggregated fuzzy decision matrix.

\begin{tabular}{|c|c|c|c|c|c|}
\hline & \multicolumn{5}{|c|}{ Aggregated fuzzy decision matrix } \\
\hline & WAM & KUNA & SPA & BNA & OMA \\
\hline $\mathrm{C} 1$ & $(0.30,0.50,0.70)$ & $(0.30,0.50,0.70)$ & $(0.60,0.80,1.00)$ & $(0.30,0.50,0.70)$ & $(0.30,0.50,0.70)$ \\
\hline $\mathrm{C} 2$ & $(0.40,0.60,0.80)$ & $(0.40,0.60,0.80)$ & $(0.30,0.50,0.70)$ & $(0.10,0.40,0.60)$ & $(0.40,0.60,0.80)$ \\
\hline C3 & $(0.60,0.80,1.00)$ & $(0.30,0.50,0.70)$ & $(0.60,0.80,1.00)$ & $(0.30,0.50,0.70)$ & $(0.60,0.80,1.00)$ \\
\hline $\mathrm{C} 4$ & $(0.10,0.40,0.60)$ & $(0.40,0.60,0.80)$ & $(0.30,0.50,0.70)$ & $(0.40,0.60,0.80)$ & $(0.10,0.40,0.60)$ \\
\hline $\mathrm{C} 5$ & $(0.40,0.60,0.80)$ & $(0.40,0.60,0.80)$ & $(0.40,0.60,0.80)$ & $(0.40,0.60,0.80)$ & $(0.40,0.60,0.80)$ \\
\hline C6 & $(0.10,0.40,0.60)$ & $(0.30,0.50,0.70)$ & $(0.30,0.50,0.70)$ & $(0.40,0.60,0.80)$ & $(0.40,0.60,0.80)$ \\
\hline $\mathrm{C} 7$ & $(0.30,0.50,0.70)$ & $(0.30,0.50,0.70)$ & $(0.30,0.50,0.70)$ & $(0.30,0.50,0.70)$ & $(0.30,0.50,0.70)$ \\
\hline $\mathrm{C} 8$ & $(0.30,0.50,0.70)$ & $(0.60,0.80,1.00)$ & $(0.60,0.80,1.00)$ & $(0.30,0.50,0.70)$ & $(0.60,0.80,1.00)$ \\
\hline $\mathrm{C} 9$ & $(0.60,0.80,1.00)$ & $(0.60,0.80,1.00)$ & $(0.60,0.80,1.00)$ & $(0.30,0.50,0.70)$ & $(0.60,0.80,1.00)$ \\
\hline $\mathrm{C} 10$ & $(0.40,0.60,0.80)$ & $(0.10,0.40,0.60)$ & $(0.30,0.50,0.70)$ & $(0.60,0.80,1.00)$ & $(0.60,0.80,1.00)$ \\
\hline $\mathrm{C} 11$ & $(0.60,0.80,1.00)$ & $(0.60,0.80,1.00)$ & $(0.60,0.80,1.00)$ & $(0.60,0.80,1.00)$ & $(0.60,0.80,1.00)$ \\
\hline $\mathrm{C} 12$ & $(0.60,0.80,1.00)$ & $(0.60,0.80,1.00)$ & $(0.60,0.80,1.00)$ & $(0.30,0.50,0.70)$ & $(0.60,0.80,1.00)$ \\
\hline $\mathrm{C} 13$ & $(0.40,0.60,0.80)$ & $(0.10,0.40,0.60)$ & $(0.30,0.50,0.70)$ & $(0.60,0.80,1.00)$ & $(0.60,0.80,1.00)$ \\
\hline $\mathrm{C} 14$ & $(0.60,0.80,1.00)$ & $(0.60,0.80,1.00)$ & $(0.60,0.80,1.00)$ & $(0.60,0.80,1.00)$ & $(0.60,0.80,1.00)$ \\
\hline $\mathrm{C} 15$ & $(0.30,0.50,0.70)$ & $(0.30,0.50,0.70)$ & $(0.60,0.80,1.00)$ & $(0.30,0.50,0.70)$ & $(0.30,0.50,0.70)$ \\
\hline
\end{tabular}

Table 3. Crisp values for decision matrix and each criterion weight.

\begin{tabular}{ccccccccccccccccc}
\hline & \multicolumn{10}{c}{ Crisp values for decision matrix and each criterion weight } \\
\cline { 2 - 11 } & C1 & C2 & C3 & C4 & C5 & C6 & C7 & C8 & C9 & C10 & C11 & C12 & C13 & C14 & C15 \\
\hline Weight & 0.56 & 0.54 & 0.68 & 0.50 & 0.60 & 0.52 & 0.50 & 0.68 & 0.74 & 0.62 & 0.80 & 0.74 & 0.62 & 0.80 & 0.56 \\
WAM & 0.50 & 0.60 & 0.80 & 0.40 & 0.60 & 0.40 & 0.50 & 0.50 & 0.80 & 0.60 & 0.80 & 0.80 & 0.60 & 0.80 & 0.50 \\
KUNA & 0.50 & 0.60 & 0.50 & 0.60 & 0.60 & 0.50 & 0.50 & 0.80 & 0.80 & 0.40 & 0.80 & 0.80 & 0.40 & 0.80 & 0.50 \\
SPA & 0.80 & 0.50 & 0.80 & 0.50 & 0.60 & 0.50 & 0.50 & 0.80 & 0.80 & 0.50 & 0.80 & 0.80 & 0.50 & 0.80 & 0.80 \\
BNA & 0.50 & 0.40 & 0.50 & 0.60 & 0.60 & 0.60 & 0.50 & 0.50 & 0.50 & 0.80 & 0.80 & 0.50 & 0.80 & 0.80 & 0.50 \\
OMA & 0.50 & 0.60 & 0.80 & 0.40 & 0.60 & 0.60 & 0.50 & 0.80 & 0.80 & 0.80 & 0.80 & 0.80 & 0.80 & 0.80 & 0.50 \\
\hline
\end{tabular}

Finally, the alternatives were ranked and consequently a compromise solution was proposed. Table 6 shows the ranking of the alternatives using S, R and Q in 
Table 4. Best and worst values for each criterion.

\begin{tabular}{cccccccccccccccc}
\hline & \multicolumn{10}{c}{ Best and worst values for each criterion } \\
\cline { 2 - 5 } & C1 & C2 & C3 & C4 & C5 & C6 & C7 & C8 & C9 & C10 & C11 & C12 & C13 & C14 & C15 \\
\hline fj $^{\sim *}$ & 0.80 & 0.60 & 0.80 & 0.60 & 0.60 & 0.60 & 0.50 & 0.80 & 0.80 & 0.80 & 0.80 & 0.80 & 0.80 & 0.80 & 0.50 \\
ff $^{\sim}$ & 0.50 & 0.40 & 0.50 & 0.40 & 0.60 & 0.40 & 0.50 & 0.50 & 0.50 & 0.40 & 0.80 & 0.50 & 0.40 & 0.80 & 0.50 \\
\hline
\end{tabular}

Table 5. S, R and Q index values for each alternative.

\begin{tabular}{cccccc}
\hline & \multicolumn{5}{c}{ S, R and Q index values for each alternative } \\
\cline { 2 - 6 } & WAM & KUNA & SPA & BNA & OMA \\
\hline S & 2.1176 & 2.5600 & 0.8399 & 3.6790 & 0.9089 \\
R & 0.7083 & 0.8333 & 0.5500 & 0.8750 & 0.6910 \\
Q & 0.5199 & 0.6609 & 0.0102 & 1.0000 & 0.2557 \\
\hline
\end{tabular}

Table 6. Ranking of alternative using S, R and Q in ascending order.

\begin{tabular}{cc}
\hline & Ranking of alternative using $\mathrm{S}, \mathrm{R}$ and $\mathrm{Q}$ in ascending order \\
\cline { 2 - 2 } By $\mathrm{T}$ & $\mathrm{T}$ \\
By R & $\mathrm{SPA}>\mathrm{OMA}>\mathrm{WAM}>\mathrm{KUNA}>\mathrm{BNA}$ \\
By Q & $\mathrm{SPA}>\mathrm{OMA}>\mathrm{WAM}>\mathrm{KUNA}>\mathrm{BNA}$ \\
\hline
\end{tabular}

ascending order. The results exhibit that the ranking orders are the same for all index values. It can be clearly seen that Saudi Press Agency (SPA) has the best quality in terms of the security policies and Content analysis of gulf press agencies.

\section{Conclusions}

In this paper, a fuzzy VIKOR framework has been adopted in ranking and evaluating the security policies and analyzing the content of five press agencies in gulf countries which are (Emirates News Agency (WAM), Kuwait News Agency (KUNA), Saudi Press Agency (SPA), Bahrain News Agency (BNA), and Oman News Agency (OMA)) where linguistic variables are applied to solve the uncertainties and subjectivities in expert decision making.

The study declares that Saudi Press Agency (SPA) has the best quality in terms of the security policies and analyzes the content of gulf press agencies. This study advantages the news seekers know that Saudi Press Agency (SPA) has the mandate and the competence to educate the public on fresh news. Besides, this paper contributes to Gulf agencies in helping them in their resolve to ensure the quality of content information and information security policies over the internet.

For future work, we are going to apply different MCDM methods and do the comparative analysis with the current technique to see which method is better in 
solving the uncertainties and subjectivities in expert decision making.

\section{Conflicts of Interest}

The author declares no conflicts of interest regarding the publication of this paper.

\section{References}

[1] Markides, C.C. (2013) Game-Changing Strategies: How to Create New Market Space in Established Industries by Breaking the Rules. John Wiley \& Sons, Hoboken.

[2] Ezer, T., Atkinson, L.P., et al. (2013) Gulf Stream's Induced Sea Level Rise and Variability along the US Mida Atlantic Coast. Journal of Geophysical Research: Oceans, 118, 685-697. https://doi.org/10.1002/jgrc.20091

[3] Burkhardt, J.M. (2017) Combating Fake News in the Digital Age. American Library Association, Chicago.

[4] Nwagboso, C.I. (2012) Security Challenges and Economy of the Nigerian State (2007-2011). American International Journal of Contemporary Research, 2, 244-258.

[5] Adebakin, M.A. and Raimi, L. (2012) National Security Challenges and Sustainable Economic Development: Evidence from Nigeria. Journal of Studies in Social Sciences, 1, 10-20.

[6] Zain, Z.M. (2018) Evaluation of the Quality of Internet Breast Cancer Information: Fuzzy VIKOR Approach. In: Karwowski, W. and Ahram, T., Eds., Intelligent Human Systems Integration, Springer, Cham, 95-101. https://doi.org/10.1007/978-3-319-73888-8_16

[7] Talib, A.M. (2015) Ensuring Security, Confidentiality and Fine-Grained Data Access Control of Cloud Data Storage Implementation Environment. Journal of Information Security, 6, 118-130. https://doi.org/10.4236/jis.2015.62013

[8] Ahmad, Z.A. and Buyong, M. (2017) Content Analysis of Online News Portal: Issues and Challenges. e-Bangi, No. 2, 164-174.

[9] Vaismoradi, M., Turunen, H., et al. (2013) Content Analysis and Thematic Analysis: Implications for Conducting a Qualitative Descriptive Study. Nursing \& Health Sciences, 15, 398-405. https://doi.org/10.1111/nhs.12048

[10] Skalski, P.D., Neuendorf, K.A., et al. (2017) Content Analysis in the Interactive Media Age. In: Neuendorf, K.A., Ed., The Content Analysis Guidebook, SAGE Publications, Inc., Thousand Oaks, 201-242. https://doi.org/10.4135/9781071802878.n7

[11] Taylor, E. (2016) The Internet in the Gulf Countries: How Issues of Internet Access and Cybercrime Impact the Region. International Security Department, Chatham House Report, 1-80.

[12] Al Abed, I., Hellyer, P., et al. (2006) United Arab Emirates Yearbook 2006. Trident Press Ltd., London.

[13] Al-Augby, S., Majewski, S., et al. (2013) Reaction to News of Oil and Gas Sector Companies in Kuwait. International Journal of Business and Social Science, 4, 76-83.

[14] Awad, T. (2010) The Saudi Press and the Internet: How Saudi Journalists and Media Decision Makers at the Ministry of Culture and Information Evaluate Censorship in the Presence of the Internet as a News and Information Medium. University of Sheffield, Sheffield. 
[15] Abdeldayem, M.M. (2015) Examining the Relationship between Agency Costs and Stock Mispricing: Evidence from the Bahrain Stock Exchange. International Journal of Economics, Commerce and Management, 3, 1-35.

[16] Hallward, M. and Bekdash-Muellers, H. (2019) Success and Agency: Localizing Women's Leadership in Oman. Gender in Management, 34, 606-618. https://doi.org/10.1108/GM-11-2017-0162

[17] Kahraman, C. (2008) Fuzzy Multi-Criteria Decision Making: Theory and Applications with Recent Developments. Springer, Berlin. https://doi.org/10.1007/978-0-387-76813-7

[18] Lu, J. and Ruan, D. (2007) Multi-Objective Group Decision Making: Methods, Software and Applications with Fuzzy Set Techniques (With CD-ROM). Imperial College Press, London. https://doi.org/10.1142/p505

[19] Bellman, R.E. and Zadeh, L.A. (1970) Decision-Making in a Fuzzy Environment. Management Science, 17, B-141-B-273. https://doi.org/10.1287/mnsc.17.4.B141

[20] Opricovic, S. (1998) Multicriteria Optimization of Civil Engineering Systems. PhD Thesis, Faculty of Civil Engineering, Belgrade, 302 p.

[21] Opricovic, S. and Tzeng, G.-H. (2004) Compromise Solution by MCDM Methods: A Comparative Analysis of VIKOR and TOPSIS. European Journal of Operational Research, 156, 445-455. https://doi.org/10.1016/S0377-2217(03)00020-1

[22] Wu, M. and Liu, Z. (2011) The Supplier Selection Application Based on Two Methods: VIKOR Algorithm with Entropy Method and Fuzzy TOPSIS with Vague Sets Method. International Journal of Management Science and Engineering Management, 6, 109-115. https://doi.org/10.1080/17509653.2011.10671152

[23] Chang, T.-H. (2014) Fuzzy VIKOR Method: A Case Study of the Hospital Service Evaluation in Taiwan. Information Sciences, 271, 196-212.

https://doi.org/10.1016/j.ins.2014.02.118

[24] Opricovic, S. (2011) Fuzzy VIKOR with an Application to Water Resources Planning. Expert Systems with Applications, 38, 12983-12990. https://doi.org/10.1016/j.eswa.2011.04.097

[25] Wang, T.C. and Chang, T.H. (2005) Fuzzy VIKOR as a Resolution for Multicriteria Group Decision-Making. The 11 th International Conference on Industrial Engineering and Engineering Management, Paris, 352-356.

[26] Sanayei, A., Mousavi, S.F., et al. (2010) Group Decision Making Process for Supplier Selection with VIKOR under Fuzzy Environment. Expert Systems with Applications, 37, 24-30. https://doi.org/10.1016/j.eswa.2009.04.063

[27] Shemshadi, A., Shirazi, H., et al. (2011) A Fuzzy VIKOR Method for Supplier Selection Based on Entropy Measure for Objective Weighting. Expert Systems with Applications, 38, 12160-12167. https://doi.org/10.1016/j.eswa.2011.03.027

[28] Chen, L.Y. and Wang, T.-C. (2009) Optimizing Partners' Choice in IS/IT Outsourcing Projects: The Strategic Decision of Fuzzy VIKOR. International Journal of Production Economics, 120, 233-242. https://doi.org/10.1016/j.ijpe.2008.07.022

[29] San Cristobal, J.R. (2011) Multi-Criteria Decision-Making in the Selection of a Renewable Energy Project in Spain: The Vikor Method. Renewable Energy, 36, 498-502. https://doi.org/10.1016/j.renene.2010.07.031

[30] Kuo, M.-S. and Liang, G.-S. (2011) Combining VIKOR with GRA Techniques to Evaluate Service Quality of Airports under Fuzzy Environment. Expert Systems with Applications, 38, 1304-1312. https://doi.org/10.1016/j.eswa.2010.07.003

[31] Jahan, A., Mustapha, F., et al. (2011) A Comprehensive VIKOR Method for Materi- 
al Selection. Materials \& Design, 32, 1215-1221.

https://doi.org/10.1016/j.matdes.2010.10.015

[32] Devi, K. (2011) Extension of VIKOR Method in Intuitionistic Fuzzy Environment for Robot Selection. Expert Systems with Applications, 38, 14163-14168. https://doi.org/10.1016/j.eswa.2011.04.227

[33] Yang, Y.-P.O., Shieh, H.-M., et al. (2013) A VIKOR Technique based on DEMATEL and ANP for Information Security Risk Control Assessment. Information Sciences, 232, 482-500. https://doi.org/10.1016/j.ins.2011.09.012

[34] Wu, Z., Ahmad, J., et al. (2016) A Group Decision Making Framework Based on Fuzzy VIKOR Approach for Machine Tool Selection with Linguistic Information. Applied Soft Computing, 42, 314-324. https://doi.org/10.1016/j.asoc.2016.02.007 